\section{From the Editor's desk}

By Peter Tyrer

\section{The maintenance of intellectual faculties}

One of the unfortunate accompaniments that commonly follows slippage into old age is the imprisonment of the intellect within the petty confines of daily living. Whereas in the past the hearing of a stumbled sentence or the sight of a secret smile may have been hardly noticed or ignored, in this tinier constrained existence they may assume special significance. The atmosphere of intrigue and suspicion that may develop is well described by Muriel Spark in Memento Mori, ${ }^{1}$ a novel centred around a mystery caller saying 'remember you must die' and in which everyone appears to be on the verge of paranoia. Muriel knew this feeling well - she developed a dexamfetamine psychosis in her earlier years - but though less florid in the elderly it is highly prevalent. Whether it is a consequence of personality change ${ }^{2}$ or a core symptom of dementia ${ }^{3}$ is difficult to determine. I suspect that it is unlikely to be part of the Craddock-Owen spectrum of core psychotic disorders being increasingly refined by genetic studies (Craddock \& Owen, pp. 92-95), and, if it is more influenced by the isolation of many in old age, could be particularly susceptible to the benefits of befriending (Mead et al, pp. 96-101).

Loss of intellect is not confined to the elderly and it is good to see that Christensen and her colleagues (pp. 126-132) have waded with further evidence into the controversy of memory loss during pregnancy and motherhood, believed by many to be scientifically proven. They do not replicate the conclusion of their colleagues close by in Sydney ${ }^{4}$ and no doubt there will be further discussion about their findings with the Digit Span Backwards Score, but as Sydneysiders are commonly regarded as knowing everyone's e-mail and mobile number but not their last name or home address, there could be geographical factors that need to be investigated too. Future investigators might take a leaf out of the research book of Köhler et al (pp. 143-149) in examining the causes of cognitive loss. Their elegant study shows the advantage of neuroimaging in elucidating the reason for intellectual impairment in late life; the presence of greater white matter intensities clearly needs replication but chronic stress appears to be much less important than blood supply. But the reasons for cognitive decline remain a puzzle and it surprises me that, despite the manifold evidence of structural and pathophysiological brain impairment in schizophrenia, reinforced by Harms et al (pp.150-157), dementia is not a more common cause of death in schizophrenia (Brown et al, pp. 116-121). Spence (pp. 161-163) identifies one of the imponderables here: it is often 'the spirit that keeps people going when they have nothing left' - a crucially important consideration that will probably remain forever beyond the probing tentacles of scientific enquiry.

\section{The art of masterly inactivity}

Soon after medical qualification I worked for an orthopaedic surgeon. Early in this attachment I saw a patient admitted as an emergency with severe back pain that seemed to be unequivocally caused by a lumbar disc protrusion. I sympathised greatly with the patient when getting a full history and the next day I duly made a case for an emergency laminectomy. 'Ah', said the surgeon, 'but have you considered MI?' After first feeling devastated that I had failed to pick up the alternative or comorbid diagnosis of myocardial infarction, he went on to explain that MI stood for masterly inactivity. He defined this as 'doing nothing but at the same time appearing to be doing something, but all the time keeping an eye open for what is going on'. My patient avoided laminectomy, at least on this occasion, and improved, and I saw many other examples of masterly inactivity in the course of the next 6 months. What impressed me most over this time was the advantage gained from the longitudinal perspective of patients and their symptoms, and I have always tried to incorporate this into my own psychiatric practice. We now live in a world where early intervention is generally considered to be superior to masterly inactivity, but the arguments are finely balanced here and I think it is time for MI to make a comeback As Parker (pp. 87-88) points out, early detection may lead to inappropriate and unnecessary treatment for disorders that have never existed as well as promoting stigma and discrimination, and even in an improving world of openness I have yet to see a history of mental illness carrying advantage in the eyes of others. Masterly inactivity did no harm for Norman Sartorius and his youthful hallucinations (see p. 88) and though we now suspect these are not of great pathological significance, ${ }^{5}$ it is only watchful inactivity that can confirm this, and the same may apply to many with early signs of personality disorder ${ }^{6}$ and psychosis, ${ }^{7}$ despite the current interest in prompt treatment, unless of course the treatment can be shown to have lasting beneficial effects. ${ }^{8}$ So rather than look for pathology in those who appear too clever by half at the age of 16 (MacCabe et al, pp.109-115), we should celebrate their achievements and just make sure that someone, somewhere, is keeping open a watchful eye.

\section{Spark M. Memento Mori. Penguin, 1973}

2 Seivewright $\mathrm{H}$, Tyrer $\mathrm{P}$, Johnson $\mathrm{T}$. Changes in personality status in neurotic disorder. Lancet 2002; 359: 2253-4.

3 Savva GM, Zaccai J, Matthews FE, Davidson JE, McKeith I, Brayne C, et al Prevalence, correlates and course of behavioural and psychological symptoms of dementia in the population. Br J Psychiatry 2009; 194: 212-9.

4 Henry JD, Rendell PJ. A review of the impact of pregnancy on memory function. J Clin Exp Neuropsychol 2007; 29: 793-803.

5 Bartels-Velthuis AA, Jenner JA, van de Willige G, van Os J, Wiersma D. Prevalence and correlates of auditory vocal hallucinations in middle childhood. Br J Psychiatry 2010; 196: 41-6.

6 Chanen AM, Jackson $\mathrm{HJ}$, McCutcheon LK, Jovev $\mathrm{M}$, Dudgeon $\mathrm{P}$, Yuen HP, et al. Early intervention for adolescents with borderline personality disorder using cognitive analytic therapy: randomised controlled trial. Br J Psychiatry 2008; 193: $477-84$.

7 Lester H, Birchwood M, Bryan S, England E, Rogers H, Sirvastava N Development and implementation of early intervention services for young people with psychosis: case study. Br J Psychiatry 2009; 194: 446-50.

8 Bywater T, Hutchings J, Daley D, Whitaker C, Yeo ST, Jones K, et al. Long-term effectiveness of a parenting intervention for children at risk of developing conduct disorder. Br J Psychiatry 2009; 195: 318-24. 